\title{
A IMPORTÂNCIA DA FORMAÇÃO DOCENTE PARA A INCLUSÃO DO ALUNO SURDO NA REDE PÚBLICA DE ENSINO
}

\author{
Michele Ferreira ${ }^{1}$ \\ Patrícia Fialho de Oliveira ${ }^{2}$ \\ Elimeire Alves de Oliveira ${ }^{3}$ \\ Ana Paula Rodrigues ${ }^{4}$ \\ Tiago Moreno Lopes Roberto ${ }^{5}$
}

RESUMO: Por muito tempo os surdos sofreram grande preconceito e foram excluídos de vários direitos, inclusive do atendimento escolar. Com o passar do tempo houve um avanço nas legislações. A Lei de Diretrizes e Bases no 9394/96 trouxe a obrigatoriedade de todos os alunos serem atendidos preferencialmente na rede regular de ensino, incluindo os surdos. No entanto, eles ainda encontram muitas barreiras e uma delas é a falta de formação docente adequada para atendê-los na rede regular de ensino. Assim, este trabalho teve como objetivo geral fazer uma problematização acerca da formação docente para o atendimento do aluno surdo na rede regular de ensino. Para tanto, valeu-se de uma pesquisa bibliográfica e documental, além de uma entrevista estruturada, cujo objetivo é verificar levantamento se essa disciplina era contemplada na matriz curricular dos cursos de formação docente. Esse intento foi plenamente atingido, na medida que demonstrou que há a presença de alunos surdos na escola regular, mas que os docentes ainda não se sentem preparados para acolhêlos, indicando a importância de sua formação adequada para atender e incluir esses alunos.

Palavras-chave: Surdez. Formação docente. Inclusão.

ABSTRACT: For a long time the deaf suffered great prejudice and were excluded from several rights, including school attendance. Over time there has been an advance in legislation. The Law of Guidelines and Bases no 9394/96 made it mandatory for all students to be served preferably in the regular school system, including the deaf. However, they still encounter many barriers and one of them is the lack of adequate teacher training to serve

\footnotetext{
I Graduada de Pedagogia pela Faculdade Futura. E-mail: ferreiramicheles65@gmail.com.

${ }^{2}$ Graduada em Pedagogia pela Faculdade Futura. E-mail: patriciasccpigro@gmail.com.

3 Professora e Coordenadora do Curso de Pedagogia na Faculdade Futura. Emailelimeire@faculdadefutura.com.br.Graduada em Direito (UNIFEV).Graduada em Pedagogia (Faculdade de Antônio Augusto Reis Neves). Graduada em Letras (UNIFEV) Especialista em Gestão Escolar (UNICAMP). Mestre em Ensino e Processos Formativos (UNESP).

${ }_{4}^{4}$ Graduada em Educação Física, Pedagogia e Administração, Mestre em Meio Ambiente e Sustentabilidade e Doutorado em Educação, Diretora da Faculdade Futura E-mail: diretoria@faveni.edu.br.

${ }_{5}$ Graduado em Psicologia (UNIFEV) Mestre em Psicologia e Saúde (FAMERP) Especialista em Saúde Mental, Professor (UNIRP) e Gestor de Políticas Acadêmicas (FUTURA) E-mail: tiagomorenolopes@hotmail.com.
} 
them in the regular school system. Thus, this work had as a general objective to make a problematization about the teacher training to attend the deaf student in the regular school system. For this, it used a bibliographic and documentary research, in addition to a structured interview, whose objective is to verify whether this discipline was included in the curricular matrix of teacher training courses. This intention was fully achieved, as it demonstrated that there is the presence of deaf students in the regular school, but that the teachers still do not feel prepared to welcome them, indicating the importance of their adequate training to serve and include these students.

Keywords: Deafness. Teacher training. Inclusion.

\section{INTRODUÇÃO}

A presente pesquisa tem por como tema a importância da formação docente para o atendimento do aluno surdo no seu processo de inclusão na rede regular de ensino. Tal estudo resultou da observação nos estágios realizados enquanto alunas do Curso de Pedagogia, em que se verificou a presença de estudantes surdos nas salas de aulas regulares, geralmente numerosas, nas quais nem sempre o professor conseguia sozinho dar a devida atenção ao aluno durante a aula, que é atendido paralelamente no Atendimento Educacional Especializado (AEE), envolvendo a Sala de Recursos.

Dessa observação surgiu o interesse pelo tema, e a seguinte questão foi levantada: os professores das salas regulares da Educação Básica recebem formação adequada em seus cursos de licenciatura para manter um nível de diálogo suficiente com um aluno surdo, de modo que impactasse na sua aprendizagem e inclusão?

A hipótese que se levanta é que para que haja a inclusão dos alunos surdos nas escolas regulares é necessário que não apenas os profissionais especializados tenham conhecimento da Linguagem Brasileira de Sinais (Libras), mas que também o professor da sala regular precisa ser orientado, tanto para acompanhar esse aluno na sala comum e até mesmo ser seu interlocutor junto aos demais alunos e com a comunidade escolar.

Por isso, é necessário o estudo do que significa ter o aluno surdo na rede regular de ensino e do que é preciso para auxiliá-lo no desenvolvimento da sua aprendizagem, como materiais adequados e, principalmente, a formação de profissionais para atendê-lo, tornando assim a sua vida e o seu cotidiano mais fácil. 
Neste sentido, este trabalho tem por objetivo geral demonstrar a importância da formação em Libras do profissional que irá atender, ensinar e auxiliar o aluno surdo na sala de aula regular, procurando estratégias de ensino para incluir o surdo e fazer com que os demais alunos aprendam com ele também. Com objetivos específicos fazer um estudo sobre a surdez e fazer um levantamento da legislação educacional que trata do tema; entender como se dá o processo de aprendizagem desses alunos e compreender o que é a Libras.

Esta pesquisa tem por justificativa estudar e compreender como se dá o processo de inclusão do aluno surdo na rede regular de ensino, na busca de evidenciar a importância da formação docente e seu papel nesse processo. É uma forma de trazer à reflexão um assunto muito importante aos profissionais de pedagogia, que atuam no espaço escolar e se deparam com esses alunos, necessitando conhecer a respeito desse assunto.

\section{DESENVOLVIMENTO}

\section{O ALUNO SURDO E O DIREITO À INCLUSÃO}

Com a promulgação da Constituição Federal de 1988, no seu artigo 205, ficou estabelecido que a educação é um direito de todos, devendo o Estado, a família, com incentivo e colaboração da sociedade, proporcioná-la, "visando ao pleno desenvolvimento da pessoa, seu preparo para o exercício da cidadania e sua qualificação para o trabalho", sendo garantido em seu artigo 208 a oferta do atendimento educacional especializado, preferencialmente na rede regular de ensino. Ou seja, todos, num sentido amplo e universal têm o direito preferencial de frequentar uma escola regular (BRASIL, I988).

Neste mesmo sentido, em 1990, o Estatuto da Criança e do Adolescente (Lei no 8.069 de 13/o7/1990) veio determinar a "igualdade de condições para o acesso e permanência na escola e atendimento educacional especializado aos portadores de deficiência, preferencialmente na rede regular de ensino".

Também em 1994, a Declaração de Salamanca veio reforçar que a instituição escolar precisava assumir o dever de educar cada estudante, na perspectiva da inclusão da diversidade, abrangendo todos que necessitam de algum tipo de necessidade especial. 
Segundo esse documento, "o princípio fundamental da escola inclusiva é o de que todas as crianças deveriam aprender juntas, independentemente de quaisquer dificuldades ou diferenças que possam ter. (BRASIL, I994).

Posteriormente a Lei de Diretrizes de Bases, 9394/96 (BRASIL,1996) reafirmou esse direito, orientando que a matrícula de todos, indistintamente, fosse realizada preferencialmente nas escolas regulares e colocou ao Estado o dever de estabelecer métodos e recursos de apoio, de forma a garantir a matrícula, a permanência e o ensino de qualidade.

Nesse mesmo sentido, a Política Nacional de Educação Especial (Decreto 6.57I/o8), determinou que todos os alunos deveriam estudar na escola comum, com a garantia da qualidade do ensino para todos, independentemente de sua condição física, psicológica, moral, econômica e social, o que necessariamente levou à inclusão do aluno surdo na escola regular.

Assim é notório que existe uma farta legislação que visa assegurar o direito do aluno surdo frequentar a rede regular de ensino, mas apenas a matrícula não garante o direito de aprender igualmente aos demais alunos. Simplesmente colocar um aluno numa sala de aula, sem dar um atendimento adequado e diferenciado não significa que este aluno será incluído e terá um aprendizado de qualidade.

A matrícula é apenas o primeiro passo, que deve ser seguido por mais ações inclusivas, sobretudo pelo professor que vá atender direta e cotidianamente esse aluno, por isso surgiram alguns desafios neste processo de inclusão. Conforme Streiechen (2012, p.I13) "a inclusão do aluno surdo no ensino regular tem gerado conflito e angústias aos profissionais envolvidos nesse processo”. Isso porque a inclusão demanda mudança de estrutura física, de ações profissionais e um desses desafios é a falta de capacitação docente.

É preciso entender que as práticas pedagógicas excludentes do passado necessitam ser deixadas para trás, possibilitando a unificação das modalidades de educação regular e especial num "sistema único de ensino caminha - se em direção a uma reforma educacional mais ampla em que todos os aluno começam a ter suas necessidades educacionais satisfeitos dentro da educação regular” MANTOAN (1997,p.ı.) 
No entanto, conforme Silva e Retondo (2008), os professores das classes comuns não possuem nenhum preparo para o trabalho pedagógico com crianças com algum tipo de deficiência; além disso os professores que realizam o Atendimento Educacional Especializado (AEE) podem contribuir muito pouco no processo de ensino realizado na classe regular, pois seu trabalho geralmente é focado em dificuldades específicas que os alunos apresentam durante a aula regular.

Segundo Silva (2009), para que o aluno que tenha alguma deficiência seja incluído e atendido conforme suas particularidades é necessário que os docentes sejam capacitados para atender a diversidade presente no contexto escolar, tendo em vista que as necessidades também são diferentes.

Embora o artigo 59 da LDB 9.394/96, em seu inciso III, determine que os sistemas de ensino devam assegurar "professores com especialização adequada em nível médio ou superior, para atendimento especializado, bem como professores do ensino regular capacitados para a integração desses educandos nas classes comuns” (Brasil, 1996, p. 44), essa formação ainda está longe de existir.

Há muito o que se fazer para atingir este ideal de formação. Conforme Lacerda (2006), as políticas públicas voltadas para o aluno surdo tem finalidade proporcionar o desenvolvimento pleno de suas habilidades, entretanto, encontram diversas limitações, mostrando que esses sujeitos, ao término da escolarização educação básica, não são capazes de ler e de escrever de modo satisfatório, prejudicando o desenvolvimento das capacidades desses alunos, uma vez que eles não conseguem um domínio adequado dos conteúdos acadêmicos.

Assim sendo, embora haja toda uma legislação que dá respaldo para a formação adequada e eficiente no atendimento aos surdos, isso não é o suficiente para assegurar a igualdade de oportunidades para todos, indistintamente, até mesmo pela falta de profissionais habilitados ou qualificados, que possam dar o atendimento integral que eles necessitam para aprender tudo que é ensinado na classe regular. 
Por isso, muitos autores entendem que a formação do professor é de grande importância e que seu conhecimento em Libras é imprescindível, pois só mediante o domínio dessa língua, que é peculiar do surdo, ele será capaz de atender o aluno adequadamente, e que "A formação do professor deve ser um processo contínuo que perpassa sua prática com alunos, a partir do trabalho transdisciplinar com uma equipe permanente de apoio." (PAULON, 2005, p.24).

\section{O SURDO E A LINGUAGEM BRASILEIRA DE SINAIS}

Conforme Agência Brasil (2019), um levantamento realizado em 2019 pelo Instituto Locomotiva em parceria com Semana da Acessibilidade Surda (SAS), em 2019, demonstrou que há io milhões de brasileiros com deficiência auditiva e dentre eles 2,3 são surdos. Esse estudo também apontou que a ausência de acolhimento e inclusão trazem grandes limitações a esses sujeitos, inclusive na educação e revelam que dentre a população surda apenas $7 \%$ tem o ensino superior completo, I5\% o Ensino Médio, 46\% o Ensino Fundamental e 32\% nenhum grau de instrução.

Atualmente os surdos têm ganhado visibilidade, mas durante muito tempo a ciência buscou a "cura" da surdez, tentando tornar o surdo uma pessoa "normal", desconsiderando a multiplicidade de sujeitos $e$ as suas especificidades. $O$ ensino era pautado no desenvolvimento do oralismo, em que se buscava que o surdo falasse, para que se tornasse igual aos ouvintes, ao passo que a língua de sinais era proibida nas escolas. Foi com o surgimento dos Estudos Culturais, fundamentados em Hall (2000) e, posteriormente, dos Estudos Surdos, que tem como principal teórico Skliar (20ı) que “outro olhar começou a ser dado à surdez" (REIS, 2013)

Conforme Marchesi (1995), há vários graus de surdez, desde deficientes auditivos leves, que têm apenas uma dificuldade de audição, mas que conseguem ouvir com ou sem o auxílio de aparelhos auditivos e que não são consideradas surdos, até aquele que não ouve absolutamente nada. Ainda assim, todos eles possuem necessidades educacionais especiais e precisam ser incluídos no ensino regular, uns mais outros com menos auxílio.

Neste sentido a Declaração de Salamanca dispõe: 
As políticas educacionais deverão levar em conta as diferenças individuais e as diversas situações. Deve ser levada em consideração, por exemplo, a importância da língua de sinais como meio de comunicação para os surdos, e ser assegurado a todos os surdos acesso ao ensino da língua de sinais de seu país. (BRASIL, 1994)

Ou seja, para que haja o processo de inclusão é necessário o reconhecimento que há uma diversidade no mundo da surdez e que, neste contexto, os surdos brasileiros possuem um sistema linguístico próprio, fundamentado no visual motor (gestos), que é a Língua Brasileira de Sinais (Libras).

Foi a Lei no 10.436 em 2002 que reconheceu a Libras como meio legal de comunicação e expressão para as comunidades surdas do Brasil. (BRASIL, 2002). Essa lei, além de reconhecer o valor e o potencial linguístico da Libras, ainda trouxe a obrigação ao Poder público e suas empresas concessionárias de que apoiem seu uso e difusão em todas suas esferas: federal, estaduais e municipais. Para tanto coloca de forma obrigatória a inclusão do ensino de Libras nos cursos de formação de Educação Especial e do Magistério, em seus níveis médio e superior, "não devendo esta substituir a língua portuguesa na modalidade escrita." (BRASIL, 2002).

Posteriormente, em 2005, o Decreto $\mathrm{n}^{\mathrm{o}}$ 5.626, no seu art. $3^{\circ}$, veio abranger outros cursos de formação docente, colocando a Libras como disciplina obrigatória nos cursos de formação de professores, tanto em nível médio como superior, trazendo o reconhecimento da Libras como a segunda língua oficial da comunidade surda brasileira:

\footnotetext{
$\S \mathrm{I}^{\mathrm{O}}$ Todos os cursos de licenciatura, nas diferentes áreas do conhecimento, o curso normal de nível médio, o curso normal superior, o curso de Pedagogia e o curso de Educação Especial são considerados cursos de formação de professores e profissionais da educação para o exercício do magistério.

$\S 2^{-}$A Libras constituir-se-á em disciplina curricular optativa nos demais cursos de educação superior e na educação profissional, a partir de um ano da publicação deste Decreto. (BRASIL, 2005).
}

A língua de sinais é considerada responsável pela descoberta da identidade do surdo, ao trazer-lhe a sensação de pertencimento a um grupo e aceitação de sua diferença. Ou seja, vem trazer a autonomia e a possibilidade desse sujeito exercer de forma plena sua cidadania. Desta forma a Libras cumpre um papel importante na comunicação dos surdos, tornando 
possíveis suas interações interpessoais, seja nas relações entre os surdos-surdos ou surdosouvintes (REIS, 2013).

Além de possibilitar essas interações, a Libras se torna responsável por instruir e mediar conhecimentos, na medida que os textos escritos em português são interpretados por ela. Para Goldfeld (1997), a Libras evita atrasos nos processos linguísticos uma vez que possibilita a internalização da linguagem e dos processos mentais, como a memorização, generalização, atenção, dentre outros, podendo ser aprendida de forma espontânea por ser sua língua natural.

Enfim, há vários autores que defendem que a aprendizagem dos surdos tenha como ponto de partida a língua de sinais, que funcione como um pré-requisito para a apreensão de outras disciplinas, mas para isso é preciso que todos os professores, independente da disciplina ministrada, saibam utilizar a Libras e ser o mediador da aprendizagem do aluno na sala de aula regular.

\section{PROCEDIMENTOS METODOLÓGICOS}

O presente trabalho foi realizado foi mediante pesquisa bibliográfica e documental, cujos procedimentos se deram a partir levantamento e leitura de livros, artigos e documentos de legislações que versam sobre o tema. Para tanto, foram selecionadas obras impressas e virtuais, por meio das palavras-chave "surdez, formação docente e inclusão" publicadas em sites acadêmicos.

Também se valeu de uma entrevista estruturada, pela qual buscou identificar, se dentre professores da Educação Básica, há formação adequada e suficiente para o atendimento de surdos na rede regular de ensino, mediante o uso da Língua Brasileira de Sinais (Libras), conforme previsto em lei.

Para tanto, o instrumento utilizado foi uma pesquisa com questões fechadas, elaborada no formulário Google Forms, disponibilizado na Plataforma Google, com questões dirigidas a professores que atuam na educação básica. 
Os sujeitos respondentes foram informados previamente sobre os objetivos da pesquisa, que se tratava de um Trabalho de Conclusão de Curso de Pedagogia, cujo objetivo era realizar uma análise sobre a importância da formação docente no processo de inclusão do aluno surdo na rede regular de ensino e, para tanto, fazer um levantamento se essa disciplina era contemplada na matriz curricular dos cursos de formação docente.

Tendo em vista estarmos passando por um período de distanciamento social, em virtude da pandemia Coronavírus- COVID 19, os entrevistados foram inicialmente contactados por telefone e posteriormente enviado o questionário via eletrônica, no qual constava o Termo de Consentimento Livre e Esclarecido (TCLE), onde todos concordaram em participar da pesquisa e autorizaram o uso e publicação de suas respostas, mediante o compromisso de que a divulgação dos resultados teria apenas fins científicos e em nenhuma hipótese haveria a identificação dos sujeitos, sendo preservadas a identidade, bem como o nome da instituição em que trabalha.

Os instrumentos de pesquisa foram enviados a quatorze docentes que atuam na Educação Básica e todos foram respondidos, e o próprio formulário permitiu a análise descritiva de cada uma das questões, a luz dos referenciais teóricos.

\section{RESULTADOS}

Seguem os dados obtidos junto aos entrevistados

1- A Instituição de Educação Básica na qual (a) Senhor(a) trabalha é:

14 responses

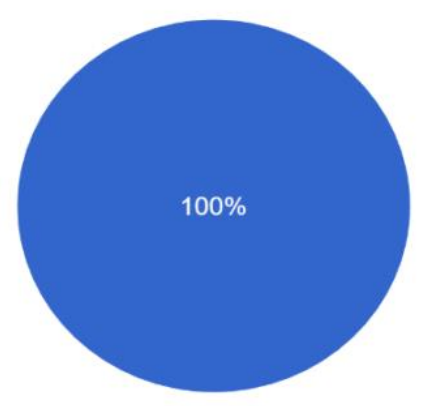


$\mathrm{Na}$ questão número I, todos os respondentes atuam na rede pública de ensino, ou seja, onde o Poder Público tem a responsabilidade objetiva tanto de fazer a inclusão do auno na rede regular, como no que se refere à formação continuada dos seus profissionais

2- Há quantos anos exerce a profissão docente 14 responses

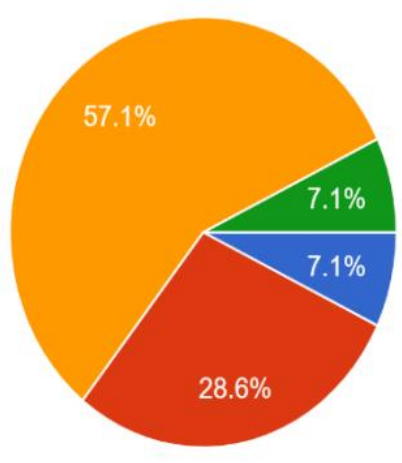

De 1 a 5 anos

De 5 a 10 anos

De 10 a 15 anos

Há mais de 20 anos

Dentre os 14 entrevistados, verifica-se a maioria, ou seja 57\%, atua entre io a 15 anos, seguido pelos profissionais que estão na profissão entre 5 a Io anos (28\%).

3- Em alguma de suas turmas houve algum aluno surdo?

14 responses

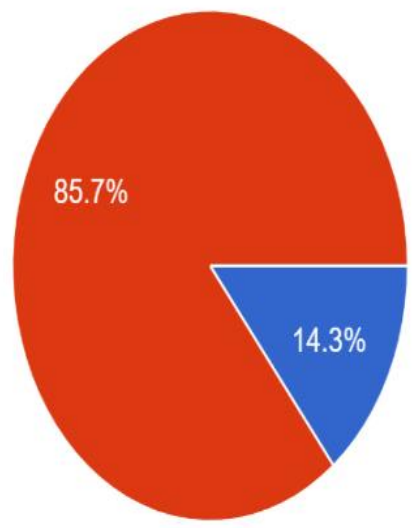


Dos 14 docentes participantes da entrevista, I4\% (dois) deles já tiveram um aluno surdo em sua turma. Levando em consideração o universo dos entrevistados, considera-se que a possibilidade de ter um aluno surdo numa sala de aula é relativamente alta.

4- Se sim, o atendimento desse aluno era feito

2 responses

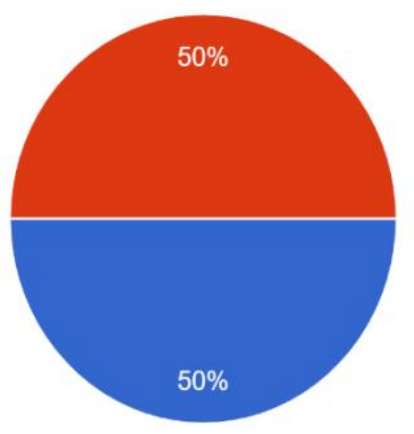

Pelo (a) Senhor (a) SIMPLESMENTE

Pelo (a) Senhor (a) COM AJUDA DE UM INTERPRETE

Dos dois professores que tiveram um aluno surdo na sala, um deles foi o único responsável pela formação dos alunos, enquanto o outro contou com o apoio de um interprete de Libras.

5- O (a) Senhor(a) tem conhecimento da Lingua Brasileira de Sinais(LIBRAS)?

14 responses

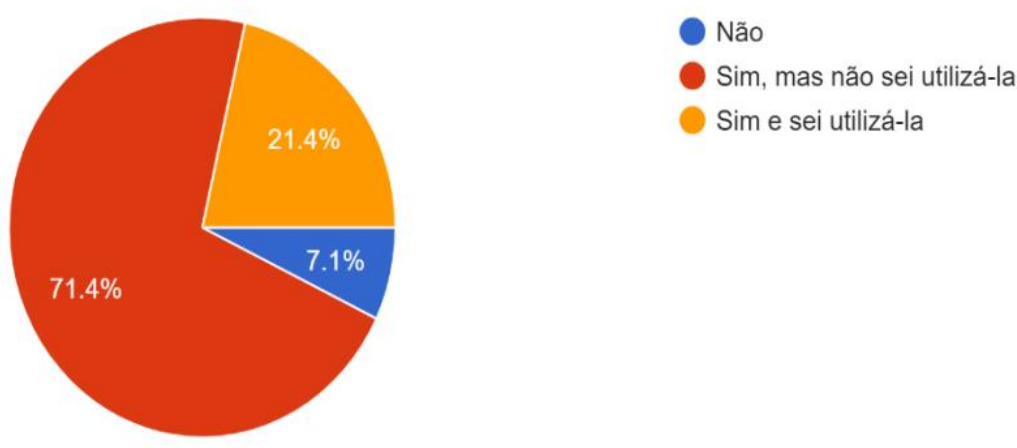

Conforme gráfico acima, embora a grande maioria tenha declarado que conhecimento da Libras (71.4\%), não sabem utilizá-la, o que nos leva a crer que esse 
conhecimento seja a respeito de sua existência no universo do surdo, mas que necessariamente não sabem praticá-la. Do total dos entrevistados, 21\% declarou que conhecem e sabe utilizá-la e 7.1\% afirmam que a desconhecem.

6- Se conhece a LIBRAS, essa formação se deu

10 responses

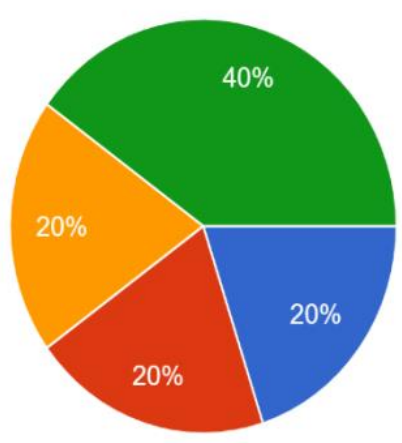

Em curso de graduação, como disciplina de LIBRAS no Curso

Em curso de graduação, como conteúdo de outra disciplina do Curso

Em curso de especialização ou pósgraduação

Em ambientes não formais de ensino

Dos io entrevistados que afirmaram ter conhecimento da Libras, observa-se que a grande maioria (40\%, que corresponde a 4 pessoas) teve essa formação em ambientes não formais de ensino, enquanto que os demais responderam de forma equitativa: $20 \%$ ( 2 ) tiveram a disciplina no Curso de graduação; 20\% (2) que tiveram conteúdos em outra disciplinas, que não específica de Libras; e 20\% (2) que aprenderam posteriormente à graduação em cursos de especialização/pós-graduação.

7- Como considera a formação em Libras durante a graduação:

14 responses

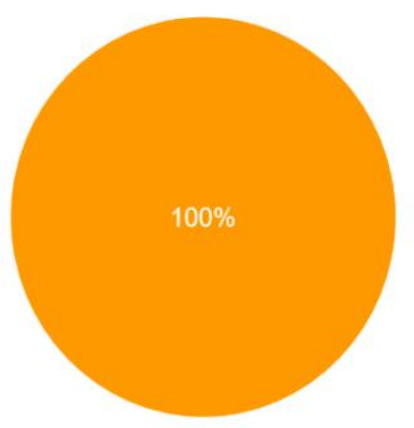


I00\% dos entrevistados afirmaram ser muito importante a formação em Libras.

8- Atribua uma nota de 0 a 1010 (na qual 0 significa nenhum preparo e 10 totalmente preparado (a) para sua capacidade de atuar na educação de surdos.

14 responses

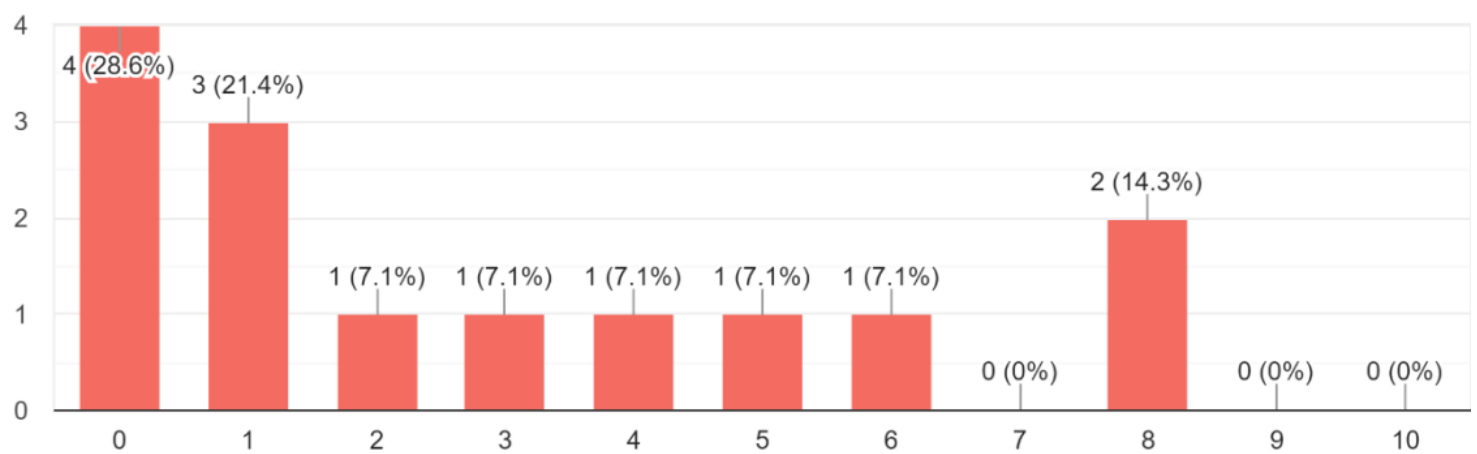

Questionados quanto seu preparo para atuar na educação de surdos, dos I4 entrevistados, numa escala de o a ıo, considerando que 5 é a média, il se manifestaram abaixo da média, sendo que $28,6 \%$ declararam sem nenhum preparo,

9- Avalie a capacidade de sua instituição numa escala de 0 a 10 (na qual 0 significa nenhum preparo e 10 totalmente preparada) no que diz resp...ber e incluir alunos surdos nas classes regulares. 13 responses

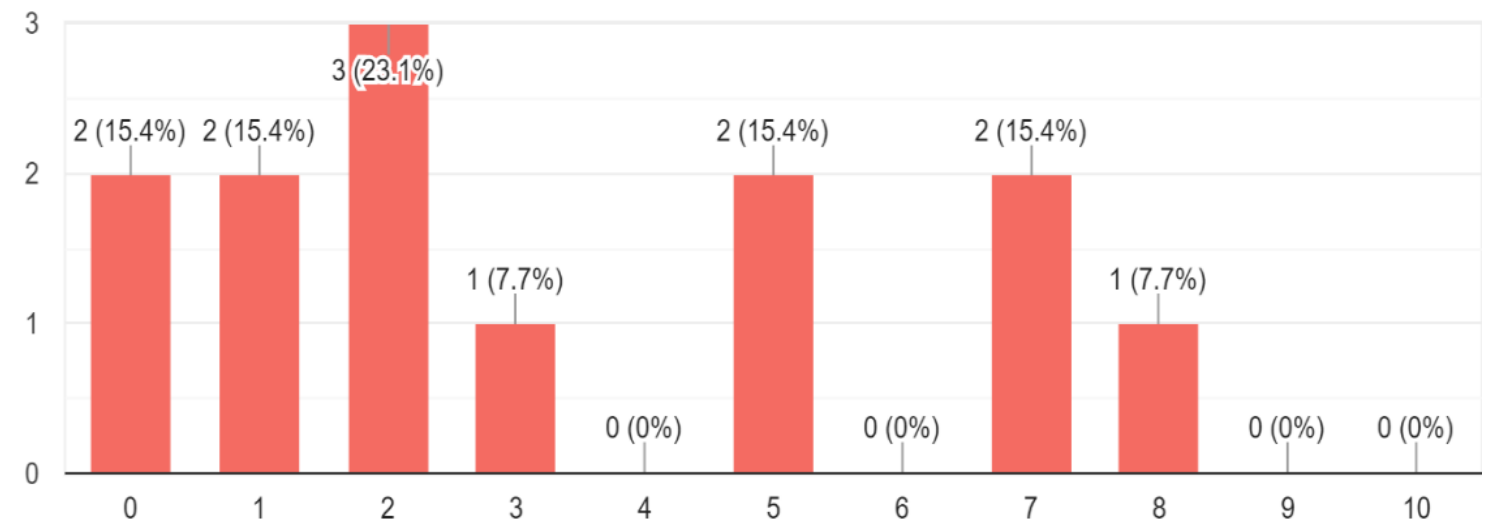


Em relação ao preparo da instituição em que trabalham, numa escala de o a ı, a maioria tem a percepção de que a escola não tem preparo suficiente para atender os surdos.

10- Como a questão da inclusão do aluno surdo é abordada na instituição que você trabalha:

13 responses

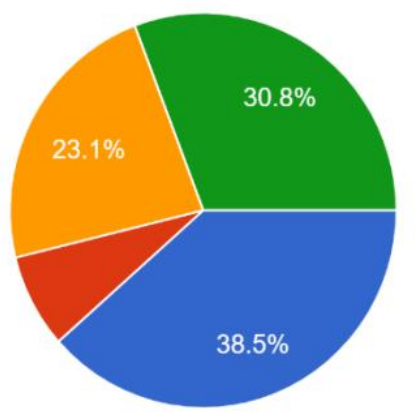

A- Não trabalha

B- Nas reuniões pedagógicas semanais

C- Em cursos proporcionados por órgãos superiores do próprio sistema

D- pelo incentivo em realizar cursos oferecidos por outros organismos ou instituições

Conforme respostas dos entrevistados, observa-se que o tema da inclusão do aluno surdo ainda é pouco trabalhado, pois na maioria das escolas (38.5\%), o assunto não é abordado; e que o incentivo é que essa capacitação seja feita por organismos e instituições externas, ou seja, fora da alçada do Estado, que é responsável direto pela formação dos seus docentes.

\section{DISCUSSÕES}

Conforme resultados da pesquisa, I0o\% dos entrevistados atuam na Educação Básica, em instituições públicas, lembrando que é onde a Constituição Federal preceitua que esse aluno tem o direito preferencial de frequentar e onde o Estado tem o dever de apoiar o uso e difusão do ensino de Libras (BRASIL, I988).

Deste total, mais da metade (57\%) desses profissionais já atuam na rede pública entre dez anos a quinze anos, ou seja, ingressaram na profissão entre os 2005 e 2015, quando a atual Lei de Diretrizes e Bases já tenha entrado em vigência, bem como a Lei no 10.436 em 2002, que reconheceu a Libras, e o Decreto $\mathrm{n}^{\mathrm{0}}$ 5.626, que colocou a Libras como disciplina obrigatória em todos os cursos de formação docente. 
No entanto somente $21 \%$ dos entrevistados conhece e sabe utilizar a Libras, embora o aluno surdo esteja presente na rede regular de ensino, conforme aponta a questão 3. Dos quatorze entrevistados, apenas dois se sentem razoavelmente preparados, numa escala de o a Io, corroborando as afirmativas de Silva e Retondo (2008), que aponta, a falta de preparo dos professores para o trabalho pedagógico com crianças com algum tipo de deficiência;

Ainda que 100\% dos entrevistados considerem muito importante o conhecimento em Libras, apenas $20 \%$ deles tiveram esta disciplina no seu curso de graduação, sendo que grande parte, $40 \%$, só foi ter contato com a Língua Brasileira de Sinais em ambientes não formais de ensino, demonstrando a necessidade da formação inicial e continuada em espaços formais e institucionalizados de ensino, conforme preconizado na LDB 9.394/96 (Brasil. 1996)), quando esta impõe aos sistemas de ensino a presença de professores com especialização adequada em nível médio ou superior, não só para atendimento especializado, mas também nas salas comuns, visando à integração desses educandos na rede regular.

Dos quatorze entrevistados, apenas dois se consideram razoavelmente preparados para atuar com alunos surdos. Também a maioria entende que a instituição que trabalha não tem preparo para receber e incluir alunos surdos nas classes regulares e o que é mais sério: $38,5 \%$ afirmam que o tema não é tratado nas formações continuadas, apesar do incentivo de receber a formação proporcionada por outros organismos que não do próprio sistema de ensino.

Essa constatação, em conformidade com os estudos de Streiechen (2012), demonstram que um dos principais desafios para a inclusão é falta de capacitação docente, bem como a mudança de estrutura física e ações profissionais.

\section{CONCLUSÃO}

Mediante a pesquisa apresentada, podemos concluir que embora exista o direito de o aluno surdo frequentar a escola regular e aprender a Libras, tais direitos não são assegurados, tendo em vista que a maioria das instituições ainda não está preparada para atendê-lo de forma adequada. 
Ficou demostrado que há dificuldades por parte dos professores para lidar com a inclusão de alunos surdos na rede regular de ensino, pois nem sempre esses docentes conhecem e sabem utilizar a Libras e também não dispõem de um auxiliar intérprete para acompanhar esses alunos, o que de um acaba dificultando seu trabalho, trazendo prejuízos ao aprendizado do aluno surdo.

Desta forma, o atendimento para os alunos que precisam de um atendimento especializado não é ofertado como o esperado, ficando claro que os professores da rede regular de ensino precisam de cursos que os qualifiquem, para que possam saber lidar com tais situações, pois é direito do aluno deficiente frequentar a escola regular e é dever do Estado acolher e incluir esses alunos na sala de aula, de modo para que possam avançar em todas as etapas de ensino, sendo de grande importância

\section{REFERÊNCIAS}

BRASIL. Constituição da República Federativa do Brasil. Brasília: Imprensa Oficial, I988.

Decreto no 5.626 de 22 de dezembro de 2005. Regulamenta a Lei no 10.436 , de 24 de abril de 2002, que dispõe sobre a Língua Brasileira de Sinais - Libras, e o art. 18 da Lei no Io.098, de I9 de dezembro de 2000.

Decreto 6.57I/o8, Dispõe sobre o atendimento educacional especializado, regulamenta o parágrafo único do art. 60 da Lei ${ }^{\circ} 9.394$, de 20 de dezembro de 1996, e acrescenta dispositivo ao Decreto $\mathbf{n}^{\circ} 6.253$, de 13 de novembro de 2007

Adolescente.

. Lei Federal n. 8069, de 13 de julho de 1990. ECA _ Estatuto da Criança e do https://crianca.mppr.mp.br/arquivos/File/publi/camara/estatuto_crianca_adolescente_ge d.pdf. Acesso em 12 Jun. 2020

Secretaria de Educação Básica. Diretoria de Apoio à Gestão Educacional. Caderno de educação especial: a alfabetização de crianças com deficiência: uma proposta inclusiva/ Ministério da Educação, Secretaria de Educação Básica, Diretoria de Apoio à Gestão Educacional. - Brasília: MEC, SEB, 2014. 48P.

Ministério da Educação. Secretaria de Educação Especial. Declaração de Salamanca: sobre princípios, políticas e práticas na área das necessidades educativas especiais. Brasília, DF: MEC; Seesp, 1994. 17 p. Disponível em: Acesso em: o9 mar. 2020. 
Secretaria de Educação Especial. Política Nacional de Educação Especial na Perspectiva da Educação Inclusiva. Brasília, DF, jan. 2008

Presidência da República. Lei de Libras. Lei no 10.436 , de 24 de abril de 2002.HTTP// www.planalto.gov.br/cuvi.03/leis/2002. acesso em: I6 de maio de 2020.

Agência Brasil País tem I0,7 milhões de pessoas com deficiência auditiva, diz estudo Agência Brasil | Disponível em https://agenciabrasil.ebc.com.br/geral/noticia/2or9Io/brasil-tem-Io7-milhoes-de-deficientes-auditivos-diz-estudo Acesso em 15 out. 2020

Goldfeld, M.. A criança surda: linguagem e cognição numa perspectiva sóciointernacionalista. São Paulo: Plexus.1997

HALL, Stuart. A identidade cultural na pós-modernidade. Rio de Janeiro: DP\&A Ed. 2000.

LACERDA, C.B.F. A inclusão escolar de alunos surdos: o que dizem alunos, professores e intérpretes sobre esta experiência. Caderno CEDES, Campinas, v. 26, n. 69, p. 163-184, 2006.

MANTOAN, Maria Tereza Egler. (Org.). 1997. A integração de pessoas com deficiência. São Paulo: Memnon. SENAC.

MARCHESI, Álvaro; COLL Cesar; PALÁCIOS Jesus. Desenvolvimento psicológico e educação. v. 3, Porto Alegre: Atrmed, 1995.

SILVA, L. M. Educação Inclusiva e formação de professores. 2009. $90 \mathrm{f}$. Monografia (Especialização Latu Sensu a distância em Educação Profissional Tecnológica Inclusiva) Instituto Federal de Educação, Ciência e Tecnologia do Estado do Mato Grosso, Cuiabá, 2009.

REIS, D.S. Formação docente e educação de surdos: um encontro com a diferença, cultura e identidade surda. / Dulcilene Saraiva Reis - Porto Velho, 2013. 147f.: il. Disponível em: http://www.ppge.unir.br/uploads/6224842I/arquivos/DISSERTA_O_DULCILENE_S ARAIVA_REIS_I806291498.pdf. Acesso em I2 Jun. 2020.

RETONDO, C. G.; SILVA, G. M. Ressignificando a formação de professores de Química para a educação especial e inclusiva: uma história de parcerias. Revista Química Nova na Escola, n.30, p. 27-33, nov. 2008.

SKLIAR, Carlos (Org.). Atualidade da educação bilíngue para surdos: interfaces entre pedagogia e linguística. Porto Alegre: Mediação, 1999.

STREIECHEN, Eliziane, Lingua Brasileira de Sinais: LIBRAS/Eliziane Streiechen; ilustrado por Sergio Streiechen- Guarapuava: UNICENTRO,2012. 136p 